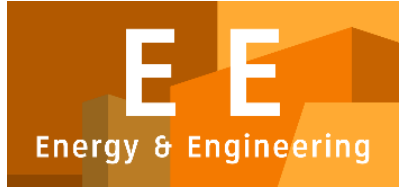

PAPER - OPEN ACCESS

\title{
Kajian Unjuk Kerja Pemanas Air Tenaga Matahari Sistim Pipa Panas Menggunakan R-134a
}
Author
: Jesayas Sembiring
DOI
: 10.32734/ee.v1i1.105
ISSN
: 2654-7031
E-ISSN
: 2654-704X

Volume 1 Issue 1 - 2018 TALENTA Conference Series: Energy and Engineering

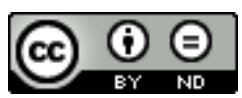

This work is licensed under a Creative Commons Attribution-NoDerivatives 4.0 International License.

Published under licence by TALENTA Publisher, Universitas Sumatera Utara
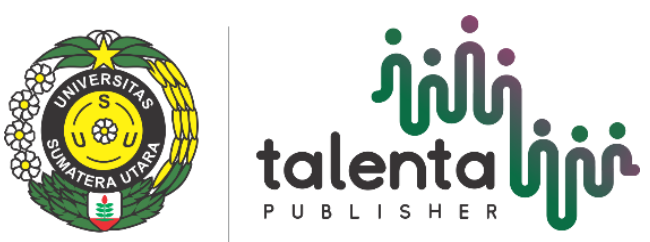


\title{
Kajian Unjuk Kerja Pemanas Air Tenaga Matahari Sistim Pipa Panas Menggunakan R-134a
}

\author{
Jesayas Sembiring ${ }^{\mathrm{a}^{*}}$, Himsar Ambarita ${ }^{\mathrm{b}}$, Farel H. Napitupulu ${ }^{\mathrm{b}}$ \\ ${ }^{a}$ Fakultas Teknik, Universitas Sumatera Utara, Medan, 20155 \\ ${ }^{b}$ Pusat Riset Sustainable Energy, Universitas Sumatera Utara, Medan 2015 \\ sembiring.jesayas@gmail.com
}

\begin{abstract}
Abstrak
Suhu bumi saat ini semakin meningkat dan sumber energi fosil semakin menipis, ini perlu disikapi secara bijak untuk menjaga keamanan dan kenyamanan kehidupan manusia dimasa depan, melalui usaha pemanfaatan energi baru dan terbarukan. Energi terbarukan adalah sumber energi yang dihasilkan dari potensi sumber daya alam, yang secara ilmiah tidak dapat habis dan dapat berkelanjutan bila dikelola dengan baik, antara lain: air terjun, tenaga angin dan tenaga matahari. Indonesia memiliki potensi tenaga matahari yang tidak terbatas karena terletak pada daerah lintasan matahari. Penelitian ini dilakukan untuk mengetahui besar efisiensi kolektor matahari menggunakan fluida kerja R134a dengan variasi tekanan dan penutup kolektor. Pemanas air tenaga matahari menggunakan fluida kerja R134a merupakan alat memproduksi air panas untuk memenuhi kebutuhan air panas dan diharapkan menjadi salah satu solusinya. Penelitian dua tahap: tahap pertama dua kaca penutup dan tahap kedua satu kaca penutup dengan variasi tekanan. Penelitian ini menawarkan tiga hal sebagai kesimpulan. Pertama, Dari hasil penelitian diketahui temperatur air meningkat seiring dengan meningkatnya tekanan fluida kerja. Kedua, Dari hasil kajian secara menyeluruh efisiensi kolektor meningkat seiring dengan meningkatnya temperatur air. Ketiga, Menggunakan dua kaca penutup kolektor lebih baik dari pada menggunakan sebuah kaca penutup kolektor. Menggunakan dua kaca penutup kolektor menghasilkan efisiensi terbaik: 35,49\% dan satu kaca penutup kolektor efisiensi terbaik: 17,77\% pada tekanan 110 psi. Secara umum dapat dikatakan bahwa: kajian unjuk kerja pemanas air tenaga matahari sistim pipa panas menggunakan fluida kerja R134a hasilnya baik, lebih efisien menggunakan dua buah kaca penutup dibandingkan hanya menggunakan satu kaca penutup kolektor.
\end{abstract}

Kata Kunci: Tenaga matahari; refrigerant; kaca penutup; pipa panas; efisiensi kolektor

\section{Pendahuluan}

\subsection{Latar Belakang}

Tenaga matahari adalah sumber daya alam yang dapat diubah menjadi energi panas melalui peralatan tertentu menjadi sumber energi dalam bentuk lain. Tenaga matahari merupakan salah satu sumber daya alam yang dapat dijadikan energi alternatif karena tenaga matahari sumber energi bersih, tidak bersifat polutif, kontinyu dan tak dapat habis.

Tenaga matahari yang sampai ke permukaan bumi, dapat dikumpulkan dan diubah menjadi energi panas melalui kolektor, kemudian ditransfer ke fluida kerja R 134a. Saat ini memperoleh air panas dengan membakar bahan bakar. Perlu diketahui penggunaan bahan bakar akan menimbulkan polusi udara yaitu terbentuknya $\mathrm{CO}$ dan $\mathrm{CO} 2$ yang 
merupakan sumber pemanasan global. Selain itu bahan bakar jenis ini merupakan sumber energi yang tak dapat diperbarui sehingga suatu saat akan habis dan perlu dicari sumber energi alternatif.

Tenaga matahari yang digunakan pada pemanas air menggunakan sisim pipa panas menggunakan prinsip termoshipon. Sistem pipa panas menggunakan refrigeran sebagai fluida kerja mulai dikembangkan untuk mendapatkan temperatur air panas yang lebih tinggi.Penggunaan refrigeran sebagai fluida kerja pada pemanas air tenaga matahari sistim pipa panas dapat beroperasi dengan alami yakni fluida kerja R134a dapat bersirkulasi tanpa menggunakan pompa mekanik.

\subsection{Tujuan Penelitian}

Tujuan dari penelitian ini adalah untuk mengetahui besar efisiensi kolektor pemanas air tenaga matahari pada tekanan 90 psi, 100 psi dan 110 psi dengan penutup kolektor satu dan dua kaca dan untuk mengetahui efisiensi kolektor terbaik masing-masing penutup kolektor pada tinjauan tekanan yang berbeda.

\subsection{Alat Pemanas Air Tenaga Matahari}

Alat pemanas air tenaga matahari memanfaatkan energi panas matahari yang cukup popular dan sudah banyak digunakan di Hotel, rumah sakit dan perumahan.

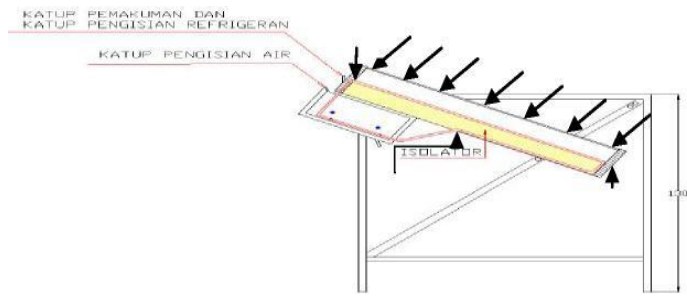

Gambar. 1. Alat Pemanas Air Tenaga Matahari

\subsection{Cara Kerja Pemanas Air Tenaga Matahari}

Energi panas yang dipancarkan oleh matahari diserap dan ditingkatkan temperaturnya oleh kolektor matahari. Energi panas tersebut dialirkan kepada pipa tembaga yang berisi refrigeran dan refrigeran naik temperaturnya. Refrigeran R134a yang naik temperaturnya akan turun massa jenisnya, sehingga akan terjadi sirkulasi alamiah, refrigeran yang panas akan naik ke bagian, tiba di tangki R134a mentransfer energi panas ke air dan air, sehingga air naik temperaturnya dan R134a turun temperaturnya maka massa jenisnya naik. Hal itu akan mengakibatkan R134a akan turun ke kolektor untuk dipanaskan oleh matahari, demikianlah sirkulasi alamiah berjalan terus sampai menjadi panas.

Penggunaan refrigeran sebagai fluida kerja pemanas air energi surya telah diteliti oleh peneliti terdahulu antara lain: Mehmet Esen dkk [2] melakukan penelitian tentang prinsip termosifon dua phasa R-134a, R-407C, dan R410A. Hasil penelitian fluida kerja yang terbaik adalah R 410a. Joseph Enaburekhan dkk (2008) melakukan pengujian R-12, Ethanol, dan R-134a. Hasil pengujian yang lebih efisien adalah R134a. Rahardjo Tirtoatmodjo dkk [6] melakukan penelitian pemanas air tenaga surya dengan penutup kolektor satu dan dua kaca. Hasil penelitian dua kaca diperoleh efisiensi lebih baik. Tekad Sitepu [5] melakukan penelitian pemanas air tenaga surya menggunakan R141b tekanan 30 psi dan R718 variasi tekanan vakum dengan sudut kolektor $30^{\circ}$. Hasil penelitian efisiensi tertinggi R141b pada tekanan 30 psi. Immanuel R. Sembiring (2015) melakukan pengujian pemanas air tenaga surya dengan R718 variasi tekanan vakum dan sudut kolektor $20^{\circ}$ dan $30^{\circ}$. Hasil pengujian efisiensi terbaik adalah pada tekanan $35 \mathrm{cmhg}$ dengan sudut kolektor $30^{\circ}$. dari penelitian ini adalah untuk mengetahui besar efisiensi kolektor pemanas air tenaga matahari pada tekanan 90 psi, 100 psi dan 110 psi dengan penutup kolektor satu dan dua kaca dan untuk mengetahui efisiensi kolektor terbaik masing-masing penutup kolektor pada tinjauan tekanan yang berbeda. 


\subsection{Energi yang Sampai di Kolektor}

Besarnya energi panas yang sampai di kolektor dihitung dengan persamaan berikut.

$$
Q_{\text {incident }}=A \int_{1}^{2} I . d t
$$

Dimana :

A = luas penampang dari pelat absorber $\left(\mathrm{m}^{2}\right)$

$\mathrm{I}=$ intensitas cahaya matahari $\left(\mathrm{W} / \mathrm{m}^{2}\right)$

\subsection{Energi yang diserap air}

Besarnya energi panas yang diserap air dihitung menggunakan persamaan berikut:

$$
Q_{u}=m_{w} C_{p, w}\left(T_{w 2}-T_{w 1}\right)
$$

Dimana :

$\mathrm{m}_{\mathrm{w}}=$ massa air $(\mathrm{kg})$

$C_{p, w}=$ Panas jenis dari air $\left(\mathrm{kJ} / \mathrm{kg} .{ }^{0} \mathrm{C}\right)$

$T_{w 1}=$ Temperatur awal air sebelum dipanaskan kolektor $\left({ }^{0} \mathrm{C}\right)$

$T_{w 2}=$ Temperatur maksimum air setelah dipanaskan kolektor $\left({ }^{0} \mathrm{C}\right)$

\subsection{Efesiensi Kolektor}

Efisiensi kolektor adalah perbandingan antara energi panas yang diserap air dengan panas incident.

Efisiensi kolektor dihitung dengan persamaan:

$$
\eta=m_{w} C_{p, w}\left(T_{w 2}-T_{w 1}\right) / Q_{\text {incident }}
$$

\section{Metode Penelitian}

\subsection{Tempat dan Waktu}

Penelitian ini dilakukan di Lantai 4 Gedung Magister Teknik Mesin FT USU, selama 5 hari yaitu dari tanggal 15 Maret 2015 sampai 5 April 2016.

\subsection{Bahan dan Alat}

Bahan yang digunakan untuk penelitian ini adalah sebagai berikut:

- Air Murni Air yang digunakan dalam penelitian ini adalah air murni dan bersih sebanyak 15 liter.

- Refrigeran R-134a Fluida kerja yang digunakan adalah refrigeran R-134a sebanyak dua tabung.

- Alat - alat penelitian

- Pemanas air tenaga matahari Skema pemanas air tenaga matahari yang digunakan pada penelitian adalah : 


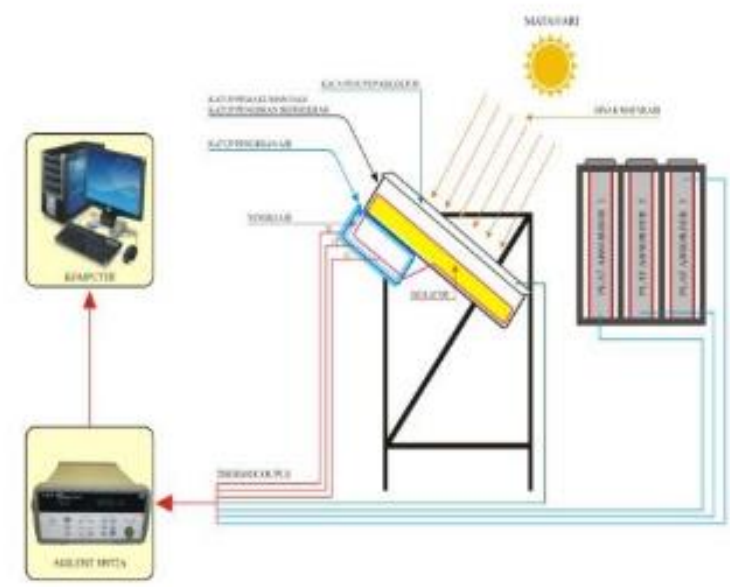

Gambar. 2. Skema Pemanas Air Tenaga Matahari

- Manifold gauge

Manifold gauge berfungsi untuk mengetahui tekanan fluida kerja R134a di pipa panas.

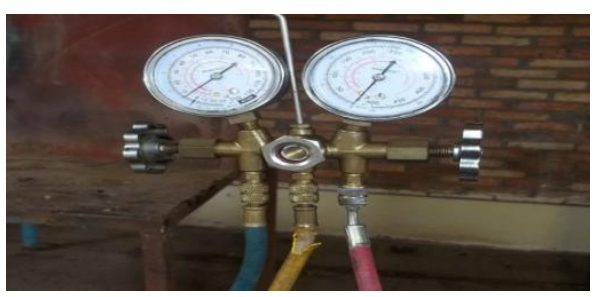

- Pompa vakum

Gambar. 3. Manifold Gauge

Pompa vakum berfungsi untuk memeriksa kebocoran pada pipa panas.

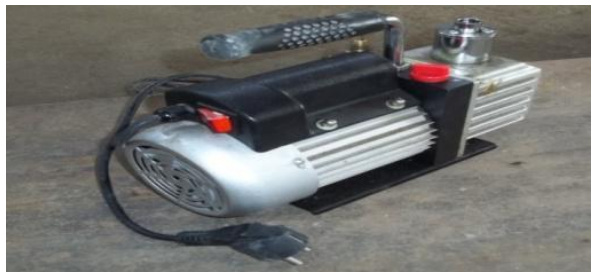

Gambar. 4. Pompa Vakum

- Agilent

Agilent berfungsi untuk membaca temperatur yang ingin diketahui temperaturnya.

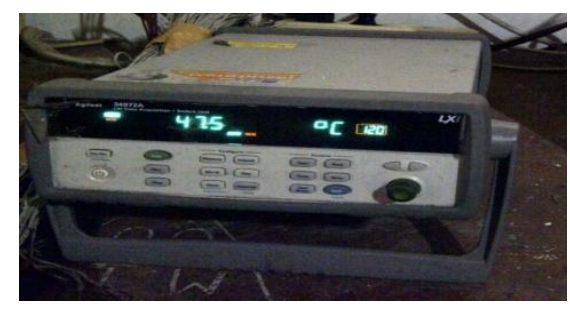

Gambar. 5. Agilent

- Data logger hobo micro station 
Alat ini dimanfaatkan untuk mengukur intensitas radiasi matahari.

\section{Hasil dan Pembahasan}

3.1. Data hasil penelitian seperti pada Tabel 1

\begin{tabular}{|c|c|c|c|c|c|c|}
\hline $\begin{array}{l}\text { Tanggal } \\
\text { Uji }\end{array}$ & Uji & $\begin{array}{l}\text { Penutup } \\
\text { kolektor }\end{array}$ & $\begin{array}{c}\overline{\text { Tekanan }} \\
\text { (psi) }\end{array}$ & $\begin{array}{c}\text { Temp. awal } \\
\left({ }^{0} \mathrm{C}\right)\end{array}$ & $\begin{array}{l}\text { Temp. maksimum } \\
\left({ }^{0} \mathrm{C}\right)\end{array}$ & $\begin{array}{l}\text { Waktu } \\
\text { (WIB) }\end{array}$ \\
\hline \multirow[t]{3}{*}{15 Maret 2016} & $\mathrm{I}$ & 2 Kaca & 90 & 27,54 & 36,47 & 14.56 \\
\hline & & & 100 & 25,84 & 40,55 & 14.10 \\
\hline & & & 110 & 25,01 & 42,89 & 14.13 \\
\hline \multirow[t]{3}{*}{21 Maret 2016} & II & 2 Kaca & 90 & 29,31 & 38,48 & 15.00 \\
\hline & & & 100 & 27,08 & 44,26 & 15.00 \\
\hline & & & 110 & 25,87 & 45,36 & 14.57 \\
\hline \multirow[t]{3}{*}{28 Maret 2016} & III & $1 \mathrm{Kaca}$ & 90 & 28,00 & 37,49 & 15.09 \\
\hline & & & 100 & 25,92 & 42,35 & 15.05 \\
\hline & & & 110 & 25,19 & 43,03 & 14.17 \\
\hline \multirow[t]{3}{*}{30 Maret 2016} & IV & $1 \mathrm{Kaca}$ & 90 & 29,69 & 38,32 & 15.58 \\
\hline & & & 100 & 27,43 & 42,07 & 15.56 \\
\hline & & & 110 & 26,16 & 44,11 & 15.52 \\
\hline \multirow[t]{3}{*}{05 April 2016} & $\mathrm{~V}$ & 2 Kaca & 90 & 29,69 & 37,93 & 14.58 \\
\hline & & & 100 & 27,43 & 42,28 & 15.00 \\
\hline & & & 110 & 26,16 & 44,42 & 14.50 \\
\hline
\end{tabular}

\subsection{Pembahasan}

\subsubsection{Dua Kaca Penutup Tekanan 90 psi}

Energi yang sampai di kolektor dihitung dengan persamaan :

$$
Q_{\text {incident }}=A \int_{1}^{2} I d t
$$

Dimana :

$A \quad=$ Luas penampang Kolektor $0.2 \mathrm{~m}^{2}$

$\int_{1}^{2} I d t=$ Intensitas matahari waktu $t_{1}-t_{2}$

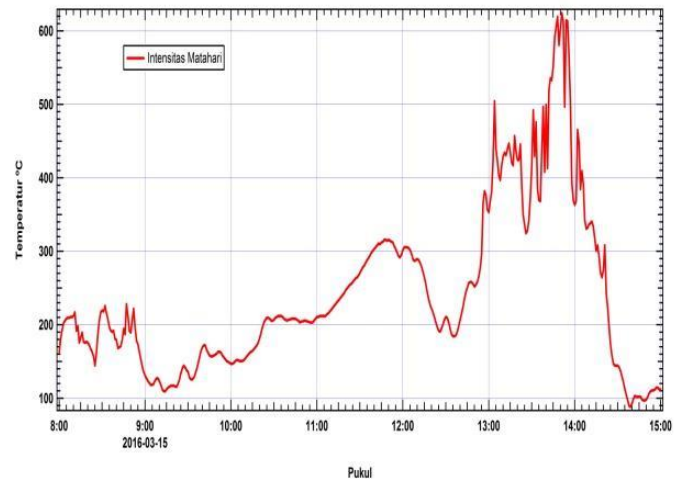

Gambar. 6. Intensitas Matahari Tanggal 15 Maret 2016 
Harga $\int_{1}^{2} I d t$ dapat dihitung dari luas dibawah kurva dengan menggunakan metode trapesium dan setiap 1 menit dihitung luas dibawah kurva dengan memakai persamaan:

$$
L_{1}=\frac{y_{0}+y_{1}}{2} \times \Delta x
$$

Dimana:

$L_{1}$ : Luas daerah dibawah kurva intensitas matahari dalam 1 menit

$y_{0}:$ Intensitas matahari awal penelitian

$y_{1}$ : Intensitas matahari 1 menit kemudian

$\Delta x$ : Waktu 1 menit

Berdasarkan data intensitas matahari hasil penelitian pada tanggal 15 Maret 2016 dapat dihitung luas daerah dibawah kurva intensitas matahari dalam satu menit yaitu:

$$
L_{1}=\frac{161.9+180.6}{2} \times 60=10.275
$$

Air telah mencapai temperatur maksimum pada pukul 14.07 WIB maka besarnya luas di bawah kurva hingga pukul tersebut adalah:

$$
L=L_{1}+L_{2}+\ldots .+L_{364}
$$

Dengan menggunakan bantuan Microsoft Excel maka didapat : $\mathrm{L}=5467653 \mathrm{Joule} / \mathrm{m}^{2}$

Maka besar energi panas yang sampai di kolektor adalah:

$$
\begin{aligned}
& Q_{\text {incident }}=0.2 \times 5467653 \\
& Q_{\text {incident }}=1093.53
\end{aligned}
$$

\section{Energi yang diserap}

Besar energi panas yang diserap air dihitung memakai persamaan 2 .

$\mathrm{m}_{\mathrm{w}}=$ massa air $=5 \mathrm{~kg}$

$C_{p, w}=$ Panas jenis dari air $=4.28 \mathrm{~kJ} / \mathrm{kg}^{0} \mathrm{C}$

$T_{w 1}=$ Temperatur awal air sebelum dipanaskan kolektor $=27.54{ }^{\circ} \mathrm{C}$

$T_{w 2}=$ Temperatur maksimum air setelah dipanaskan kolektor $36.47{ }^{\circ} \mathrm{C}$

Sehingga $Q_{u}=5 \times 4.18(36.47-25.54)=186.637 \mathrm{~kJ}$

\section{Efesiensi Kolektor}

$$
\eta=Q_{u} / Q_{\text {incident }}
$$

Maka efisiensi kolektor dua kaca penutup pada tekanan 90 psi adalah

$$
\eta=\frac{186.637}{1204.21}=0.1550
$$

\subsubsection{Dua Kaca Penutup Tekanan 100 psi}

Energi panas yang sampai di kolektor

$$
L_{1}=\frac{161.9+180.6}{2} \times 60=10275
$$

Air mencapai temperatur maksimum jam 14.10 WIB maka luas dibawah kurva hingga jam tersebut adalah 


$$
L=L_{1}+L_{2}+\ldots \ldots+L_{363}
$$

Menggunakan bantuan Microsoft Excel maka didapat : $\mathrm{L}=5264745 \mathrm{Joule} / \mathrm{m}^{2}$

Maka besar energi panas yang sampai di kolektor adalah:

$$
\begin{aligned}
& Q_{\text {incident }}=0.2 \times 5264745 \\
& Q_{\text {incident }}=1052.949 \mathrm{~kJ}
\end{aligned}
$$

\section{Energi yang diserap}

Besar energi panas yang diserap air dihitung memakai persamaan 2.

$\mathrm{m}_{\mathrm{w}}=$ massa air $=5 \mathrm{~kg}$

$C_{p, w}=$ Panas jenis dari air $=4.18 \mathrm{~kJ} / \mathrm{kg}^{0} \mathrm{C}$

$T_{w 1}=$ Temperatur awal air sebelum dipanaskan kolektor $=26.93{ }^{\circ} \mathrm{C}$

$T_{w 2}=$ Temperatur maksimum air setelah dipanaskan kolektor $42.89^{\circ} \mathrm{C}$

Sehingga $Q_{u}=5 \times 4.18(42.89-25.01)=373.692 \mathrm{~kJ}$

\section{Efesiensi Kolektor}

$$
\eta=Q_{u} / Q_{\text {incident }}
$$

Maka efisiensi kolektor dua kaca penutup pada tekanan 90 psi adalah

$$
\eta=\frac{373.692}{1052.949}=0.3549
$$

\section{Kesimpulan}

Dari hasil penelitian diketahui temperatur air meningkat seiring dengan meningkatnya tekanan fluida kerja dan dari hasil kajian secara menyeluruh didapat efieiensi kolektor meningkat seiring dengan meningkatnya temperatur air. Menggunakan dua kaca penutup kolektor lebih baik dari pada menggunakan sebuah kaca penutup kolektor. Menggunakan dua kaca penutup kolektor menghasilkan efisiensi terbaik:35,49\% dan satu kaca penutup efisiensi terbaik: $17.77 \%$ pada tekanan 110 psi.

Hasil penelitian ini dapat dijadikan sebagai sumbangan pemikiran bagi peningkatan kehidupan masyarakat dan bermanfaat sebagai sumbangan informasi kepada pembuat keputusan organisasi baik pemerintah maupun swasta. Kajian pemanas air tenaga matahari sistim pipa panas menggunakan fluida kerja R134a hasilnya cukup baik, sehingga dapat dijadikan sebagai solusi mengatasi krisis energi dan salah satu solusi mengurangi kenaikan suhu Bumi.

\section{References}

[1] Eneburekhan, J., Yakasai, U. T. (2008). Performance evaluation of a refrigerant-charged integrated solar water heater in Northern Nigeria, Desalination 243 (2009) 208 - 217.

[2] Esen, M., Esen, H. (2005). Experimental investigation of a two- phase closed thermosiphon solar water heater, Solar Energy 79 (2005) 459 468.

[3] Hossain, M.S., Saidur, R., Fayaz.H.,Rahim, N.A., Islam, M.R., Ahamed J.U., Rahman M.M (2011). Review on solar water heater collector and thermal energy performance of circulating pipe, Renewable and Sustainable Energy Reviews 15 (2011) $3801-3812$.

[4] Hussein, H.M.S. (1997). Theoretical and eksperimental investigation of a wickless heat pipe flat plate solar collector. PhD Thesis . Faculty of Engineering Cairo University.

[5] Sitepu, Tekad. (2015). Kajian perpormans pemanas air tenaga surya sistem pipa panas menggunakan fluida kerja R718 dan R141b.

[6] Tirtoatmodjo, R., Ekadewi, A. Handoyo (1999). Unjuk kerja pemanas air jenis kolektor surya plat datar dengan satu dan dua kaca penutup. 